\title{
Miocene reservoir rocks: pore throat size distribution as a strong controller on petrophysical attributes is a reflection of facies change
}

\author{
Osama M. Elnaggar ${ }^{1}$ (1) $\cdot$ Mostafa G. Temraz ${ }^{2}$
}

Received: 15 March 2017 / Accepted: 26 November 2017 / Published online: 12 December 2017

(c) The Author(s) 2017. This article is an open access publication

\begin{abstract}
Pore throat size distribution (PSD) is considered a finger print for each rock type and has strong effects on many petrophysical parameters, so a comparative study was done on irregular subsurface rock samples that belong to Kareem and Rudeis Formations of middle and early Miocene, respectively. These samples were collected from San El-Hagar-1 well which is located to the East of the Nile Delta to show the effect of the different lithologies on pore throat size distribution and hence many related reservoir parameters such as displacement pressure, macroporosity, microporosity, mean hydraulic radius and permeability distribution function (PDF). For achieving the previous purpose, helium porosity and capillary pressure by mercury injection were carried out. Permeability measurements were canceled due to the non-cylindrical irregular nature of the tested samples. Porosity showed a great difference between the results of the samples of the two formations. Capillary pressure results showed the presence of characterized pore throat size distribution and hence capillary pressure-derived parameters for samples of each formation. PDF showed that samples of Kareem Fm. have better reservoir flow properties (permeability) in contrast to those of Rudeis Fm. which have tight reservoir flow properties. In addition, petrographical study through thin sections and scanning electron microscope displayed the presence of two facies which are feldspathic quartz wacke (sandstone facies) of Kareem Fm. and bioclastic sandy wackestone (calcareous facies) of Rudeis Fm. All results were consistent and confirmed the influence of facies change on PSD and hence the reservoir parameters.
\end{abstract}

Keywords Pore size $\cdot$ Distribution $\cdot$ Reflection $\cdot$ Facies change

\section{Introduction}

The studied samples represent Kareem and Rudeis Formations that belong to middle and early Miocene, respectively, and were obtained from San El-Hagar-1 well, which is located at the East of the Nile Delta (lat. $30^{\circ} 29^{\prime} 13^{\prime \prime} \mathrm{N}$, long. $\left.31^{\circ} 50^{\prime} 53^{\prime \prime} \mathrm{E}\right)$ and was drilled to a total depth of about $3772 \mathrm{~m}$ by Continental Delta Oil Company (Fig. 1). The Nile Delta is a landmark in northeastern Africa where the longest river in the world, the Nile River empties into the Mediterranean Sea. The Nile Delta represents the southeastern part of the Eastern Mediterranean basin. The Nile Delta basin like similar deltas around the world forms a major

Osama M. Elnaggar

osama_221@yahoo.com

1 Production Department, Egyptian Petroleum Research Institute (EPRI), Nasr City, Cairo, Egypt

2 Exploration Department, Egyptian Petroleum Research Institute (EPRI), Nasr City, Cairo, Egypt gas and condensate province, with only small amounts of oil increase with the age of the reservoir. The Oligocene and Lower Miocene shales are considered sources of some hydrocarbon basins, probably reaching thermal maturity in the Pliocene. Also as in the Northern Egypt basin, Jurassic and Cretaceous source rocks are contributed. The nature of the basement beneath the sedimentary succession of the Nile Delta basin is almost entirely unknown. The prospective section starts with Mesozoic strata (including potential source rocks) at the base, probably resting on crystalline basement. The Mesozoic succession represents a rifted passive margin, formed at the opening of the Neo-Tethys Ocean in the Late Triassic to Early Jurassic. Proven reservoirs, with known accumulations, extend from Oligocene to Pleistocene in age; all are sands or sandstones. Pliocene reservoirs (Kafr El Sheikh and El Wastani formations) have recently proved to be exceptionally prolific and of very high quality; they include slope channels and deep water fan sands. Many subsurface studies were done on the Nile Delta to explore its oil potentiality, and they defined the stratigraphic units in

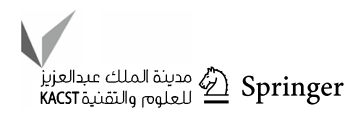


Fig. 1 Location and stratigraphic column of San ElHagar-1 well after El Sheikh et al. (2016)

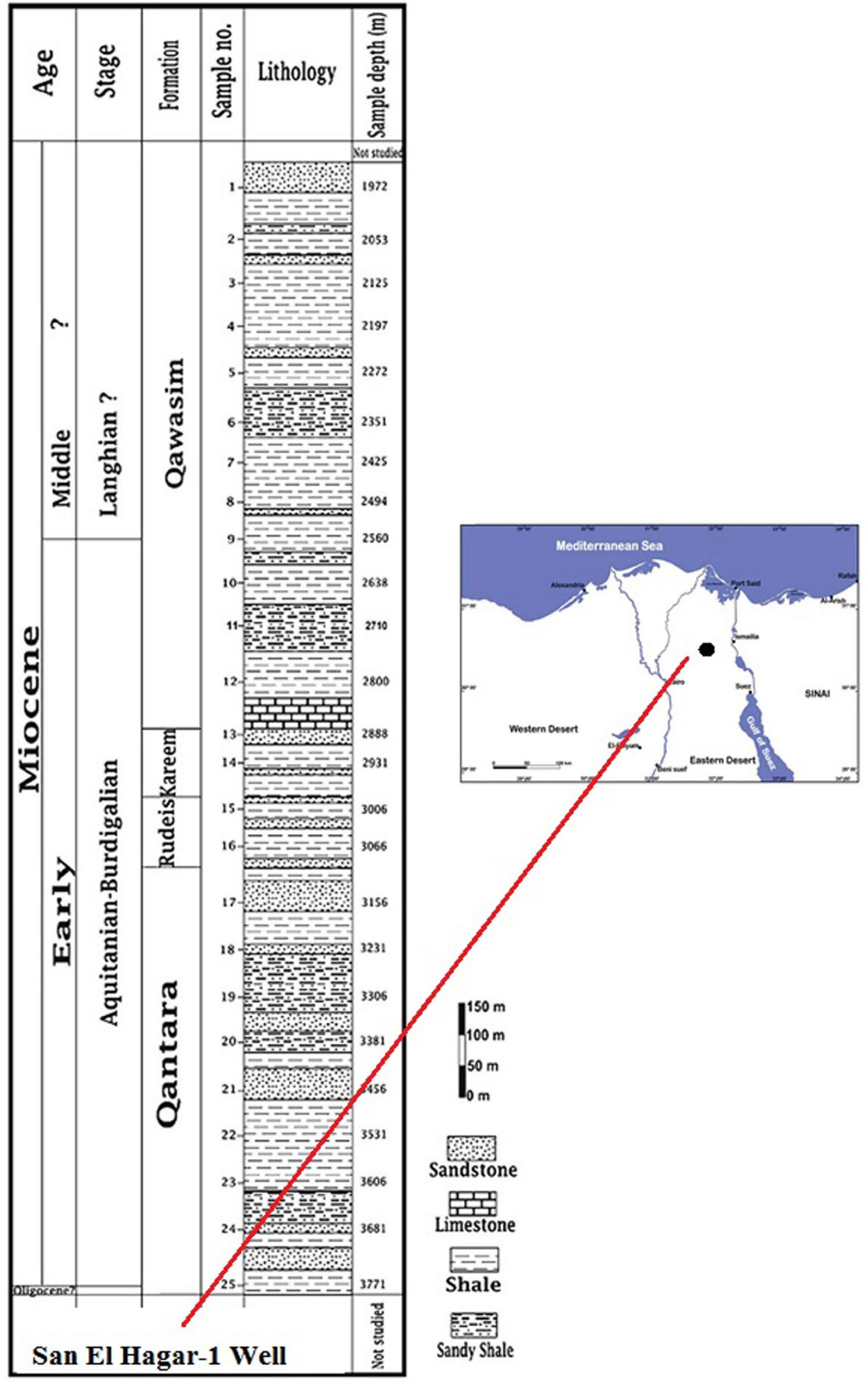

San El-Hagar-1 well from base to top (Qantara Formation of Oligocene, and Rudeis, Kareem and Qawasim Formations of Miocene age) Zaghloul et al. (1979), Abdou (2002), Cherif et al. (1993) and Ismail et al. (2010).
The studied two groups of samples of Miocene age display different lithological aspects; these differences affect the petrophysical attributes such as pore throat size distribution (PSD) and subsequently affect mostly all reservoir 
properties. Hence, PSD is the main target of this work, means the relative abundance of each pore throat size in a representative pore volume of rock sample and is considered an important entrance to understand reservoir behavior during production and establish many useful correlations using PSD-related parameters. For instance, PSD is an important factor for permeability prediction where many permeability models have described pore spaces in terms of the radii of a series of capillary tubes and the total number of these capillary tubes was equated to porosity; consequently, permeability is a function of pore radius squared and porosity (Eq. 1), Amyx et al. (1960).

$K=\phi r^{2} / 8$

where $K$ is in $\mathrm{cm}^{2}$ or in $\mu \mathrm{m}^{2} ; \phi$ is a fraction.

Another an important equation (Eq. 2) known as Winland's equation used and published by Kolodzie Jr (1980), relates porosity, permeability and a useful parameter which is the pore throat size at $35 \%$ mercury saturation.

$\log r_{35}=0.732+0.588 \log k_{\text {air }}-0.864 \log \phi$

where $r_{35}=$ the pore aperture radius corresponding to the 35 th percentile of mercury saturation. $K_{\text {air }}=$ air permeability (md). $\phi=$ porosity (\%).

Also hydrocarbon saturation in a reservoir is strongly related to PSD as capillary pressure, that is, for oil to accumulate in a geological trap and form a reservoir, the pressure in the oil phase must be higher than that in the water phase of reservoir. If the pressure in the oil is only slightly greater than that in the water phase, the oil will enter only large pores of PSD, but if the pressure within the oil phase is high enough, then oil saturation would be different where the oil can enter large pores in addition to narrow pores of PSD. Due to the absence of permeability measurements, permeability distribution function (PDF) was used instead to show qualitatively which group of the studied samples of the two formations is more permeable than the other one, based on pore throat range covered by the distribution. This work aims to display the impact of the lithological change on the pore system or pore throat size distribution which is a strong controller on many petrophysical reservoir properties.

\section{Materials and techniques}

Subsurface samples were collected from San El-Hagar-1 well to represent Kareem and Rudeis Formations of middle and early Miocene age, respectively. The irregular noncylindrical samples were cleaned using toluene and methanol to remove hydrocarbon and salts, respectively, and then dried using a drying oven. Porosity values were measured using both matrix-cup helium porosimeter (Heise Gauge type) for grain volume calculation and DEB-200 instrument which follows Archimedes principle to determine the sample bulk volume. Air permeability measurements were canceled due to the irregular nature of the tested samples. Capillary pressure by mercury injection up to 30,000 psi was measured using 'Micromeritics' apparatus, where a clean and dry sample was loaded into a glass penetrometer consisting of a sample chamber attached to a cylindrical coaxial capacitor capillary stem. The penetrometer assembly with the sample were loaded into the mercury injection apparatus. The assembly was initially filled with mercury under a vacuum. Mercury was forced into the sample at low pressure, about 0.7 psia, which was maintained until the stabilized condition was reached. The process was repeated through many pressures up to a maximum of 30,000 psia. The volume of mercury injected at each pressure was determined by the capacitance change in the capillary stem. The unsaturated pore volume was estimated as percentage of pore spaces volume not filled with mercury at $30,000 \mathrm{psia}$. On the other hand, the studied samples were described petrographically through thin sections using polarized microscope and scanning electron microscope (SEM), Model Jeol 5300 JSM, Japan, to detect the pore morphology.

Table 1 Petrophysical properties of the studied samples

\begin{tabular}{|c|c|c|c|c|c|c|c|c|}
\hline Fm. & Sample & $\begin{array}{l}\text { First peak posi- } \\
\text { tion }(\mu \mathrm{m})\end{array}$ & $\begin{array}{l}\text { Second peak } \\
\text { position }(\mu \mathrm{m})\end{array}$ & $\begin{array}{l}\text { Entry pres- } \\
\text { sure (psi) }\end{array}$ & $\begin{array}{l}\phi \text { behind } \\
\text { macropores (\%) }\end{array}$ & $\begin{array}{l}\phi \text { behind } \\
\text { micropores (\%) }\end{array}$ & $\operatorname{MHR}(\mu \mathrm{m})$ & $\phi(\%)$ \\
\hline \multirow[t]{6}{*}{ Kareem } & 1 & 1.442 & 0.030 & 20.1 & 15.0 & 65.1 & 0.951 & 29.4 \\
\hline & 2 & 0.940 & 0.030 & 60.2 & 1.9 & 84.2 & 0.423 & 29.9 \\
\hline & 3 & 1.785 & 0.037 & 30.0 & 18.6 & 67.3 & 0.925 & 28.3 \\
\hline & 4 & 1.439 & 0.030 & 49.9 & 9.7 & 69.1 & 0.585 & 27.0 \\
\hline & 5 & 1.795 & 0.037 & 50.2 & 20.0 & 63.2 & 0.750 & 27.5 \\
\hline & 6 & 1.440 & 0.030 & 30.0 & 9.9 & 66.7 & 0.686 & 27.5 \\
\hline \multirow[t]{3}{*}{ Rudeis } & 7 & 0.000 & 0.072 & 669.1 & 0.0 & 100.0 & 0.036 & 10.1 \\
\hline & 8 & 0.000 & 0.087 & 712.7 & 0.0 & 100.0 & 0.045 & 13.0 \\
\hline & 9 & 0.000 & 0.087 & 561.5 & 0.0 & 100.0 & 0.051 & 11.0 \\
\hline
\end{tabular}




\section{Results and discussion}

\section{Petrophysical attributes}

Petrophysical investigation showed different petrophysical properties of the studied samples of the two formations. Table 1 displays all petrophysical values of the studied samples.

Results of capillary pressure by mercury injection showed the presence of two pore systems characterized by definite pore throat size distributions for each, which are bimodal PSD of Kareem and unimodal PSD of Rudeis Fms., respectively (Figs. 2, 3). Swanson (1985) defines the tight pores which could be accessed under high pressure values due to their very narrow pore throats as micropores or microporosity where they do not contribute to fluid flow or they are pores whose dimensions are smaller than those contributing to the rock's permeability. According to Amaefule et al. (1993), pores are classified based on throat radii into micropores whose throat size is less than $0.5 \mu \mathrm{m}$, mesopores whose throat size lies between $0.5-1.5 \mu \mathrm{m}$ and
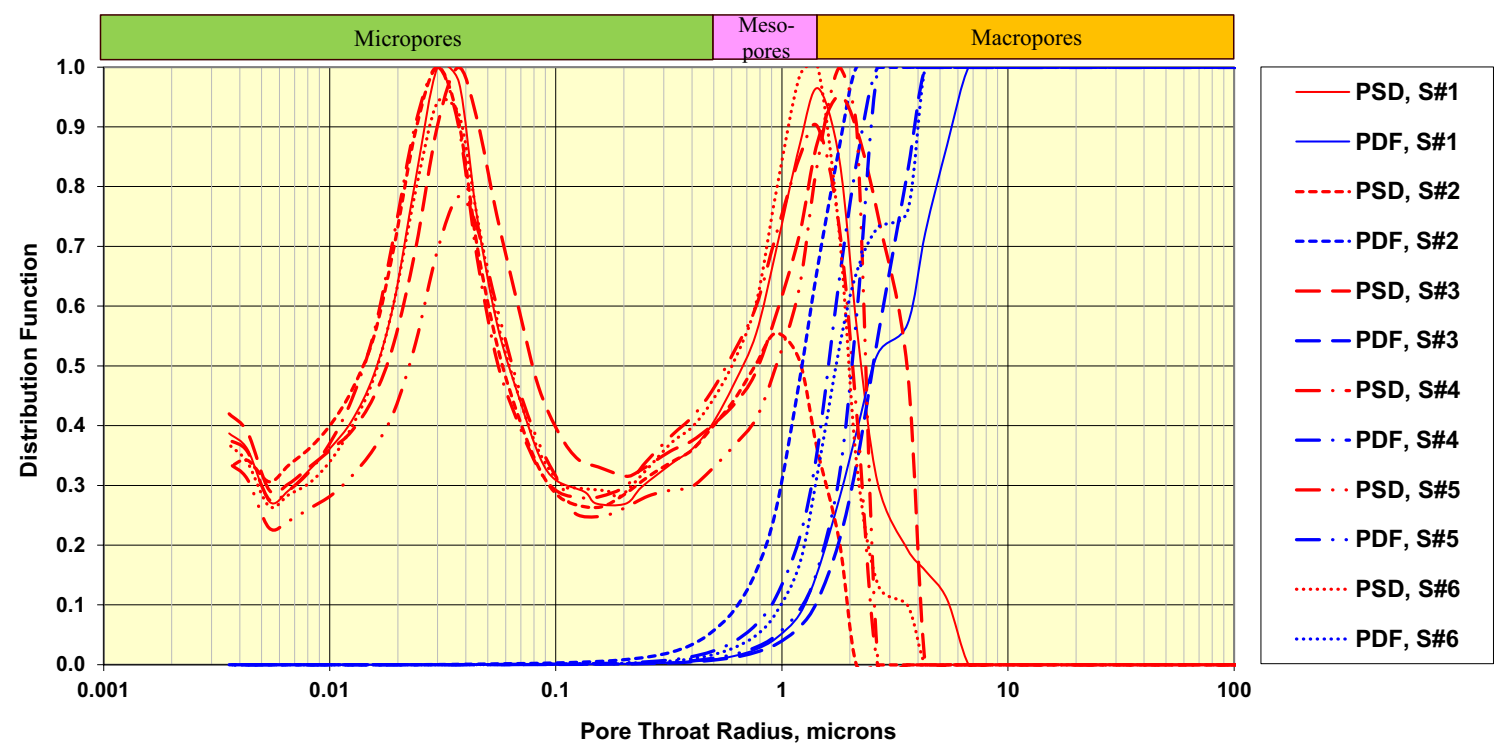

Fig. 2 PSD and PDF versus pore throat radii, Kareem Fm. samples

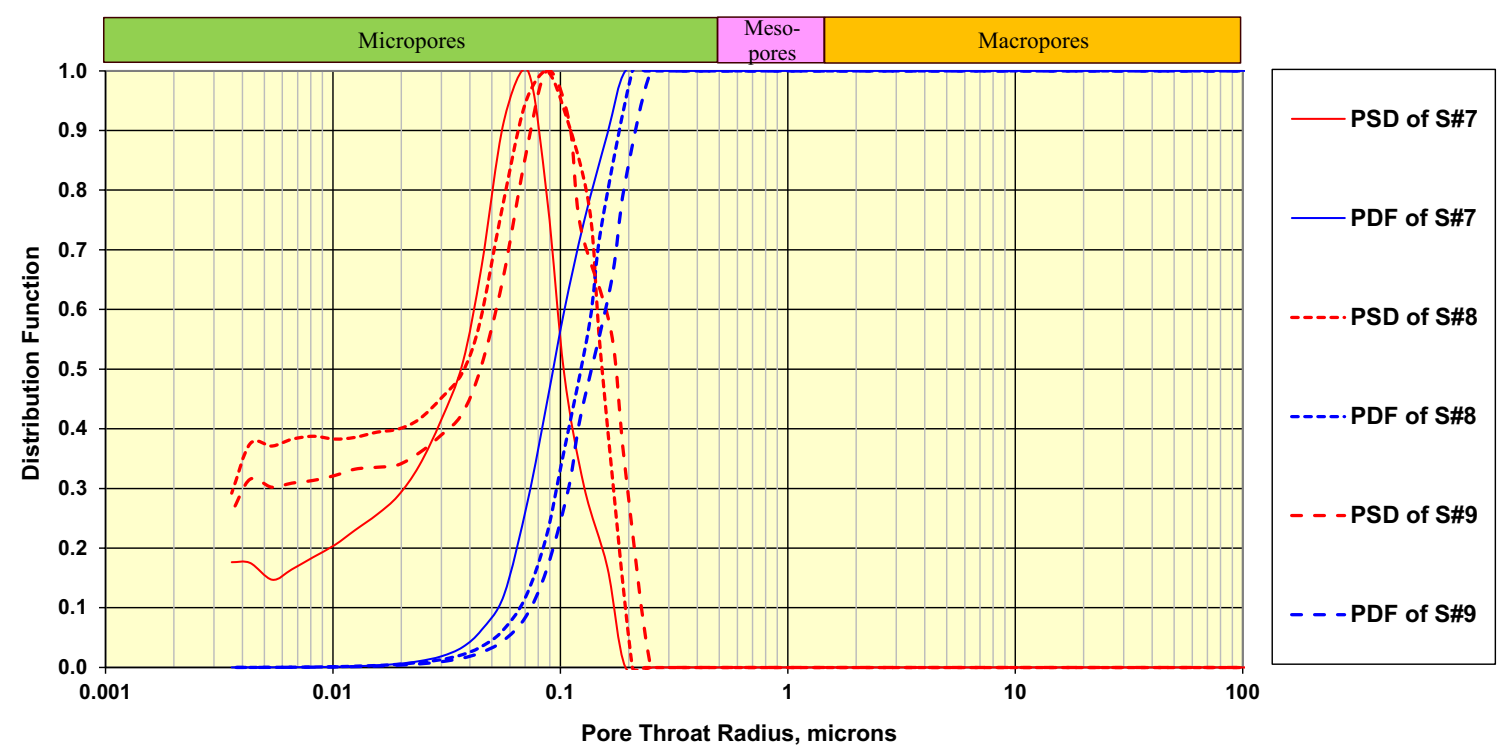

Fig. 3 PSD and PDF versus pore throat radii, Rudeis Fm. samples 
macropores whose throat size is larger than $1.5 \mu \mathrm{m}$. It is noted that PDFs of sandstone Kareem Fm. samples (Fig. 2) extend mainly over values representing macropores and mesopores and insignificantly over micropores region, but for calcareous Rudeis Fm. samples (Fig. 3), PDFs totally lie within micropores region; this indicates that Rudeis Fm. samples have very tight flow nature compared with Kareem
Fm. samples. Results of Kareem Fm. show the presence of two peaks pore system: one peak reflects sandstone coarser pores (Fig. 9a, d) and is characterized by large values that lie within macropores and mesopores zones where it ranges from 0.94 to 1.795 microns, and the second peak reflects finer pores within clays or very fine sand grains and is characterized by very low values that lie in micropores interval
Fig. 4 Tested samples versus peak positions

Fig. 5 Tested samples versus entry pressure, $\mathrm{psi}$
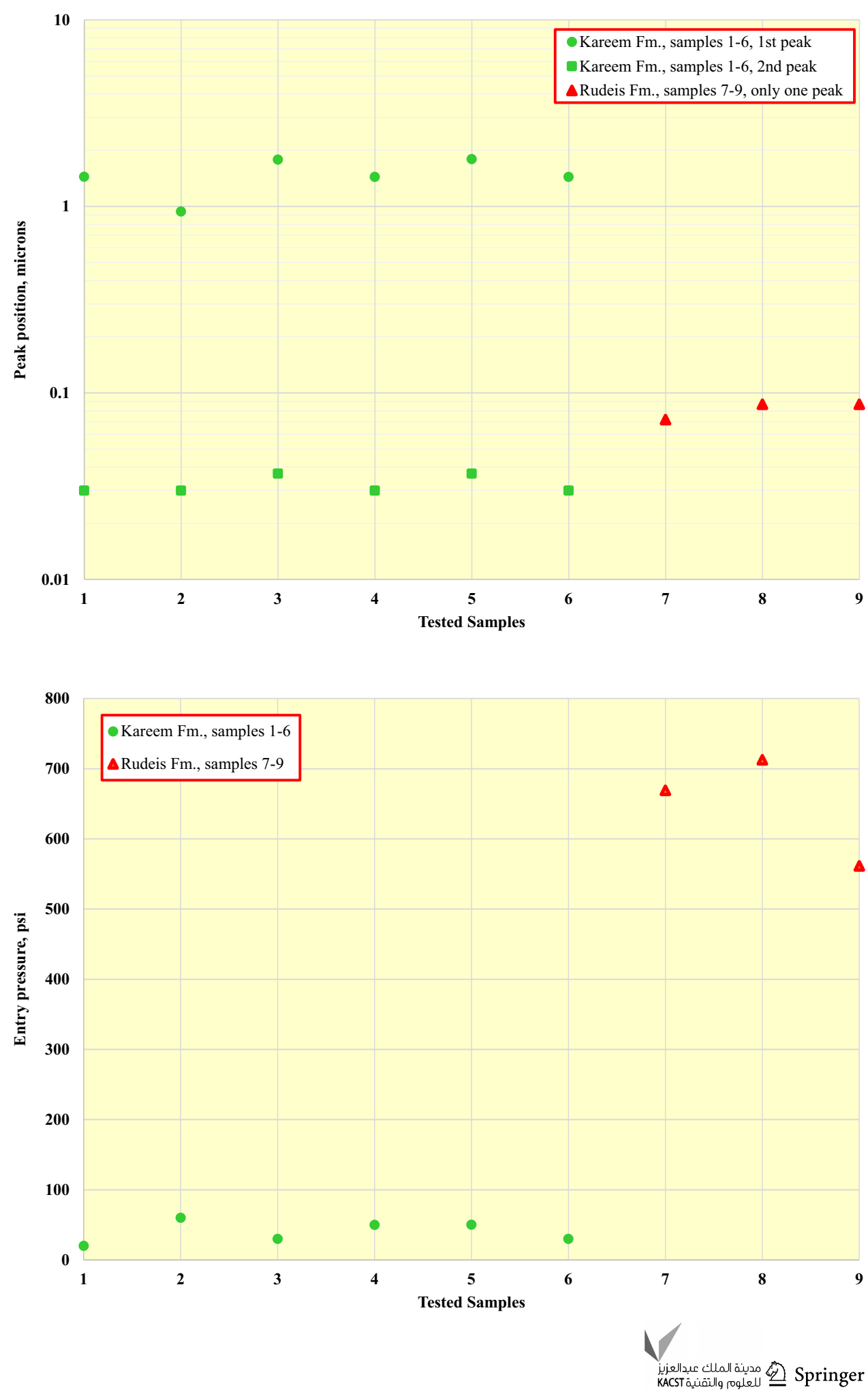
which are about 0.03 microns (Table 1 and Figs. 2, 4), but for Rudeis Fm., characterized by tight nature (Fig. 9c) there is nearly one peak pore system of low value that lies in micropores zone and ranges from 0.072 to 0.087 microns (Table 1 and Figs. 3, 4). The presence of coarser pores of Kareem Fm. samples is reflected in low entry pressure values, and the absence of these pore types in the case of Rudeis Fm. samples and the prevalence of micropores (tight flow properties) are reflected in high entry pressure values (Table 1 and Fig. 5). According to Sneider's (1987), Kareem Fm. samples represent reservoir rocks where their displacement pressures are lower than 100 psi and range from 20.1 to 60.2 psi, in contrast to Rudeis Fm. samples which represent non-reservoir rocks where their displacement pressures are more than $100 \mathrm{psi}$ and range from 561.5 to $712.7 \mathrm{psi}$ (Table 1 and Fig. 5).

Kareem Fm. samples are characterized by an amount of porosity lying behind macrothroats whose sizes are more than $1.5 \mu \mathrm{m}$ (Table 1 and Fig. 6), where they caused good flow properties for these samples (Fig. 2); in contrast, Rudeis Fm. samples are characterized by porosity values lying totally behind microthroats whose dimensions are less than $0.5 \mu \mathrm{m}$ (Table 1 and Fig. 6), so they are responsible for the tight permeability distribution (Fig. 3), confirming that samples of Kareem Fm. have reservoir flow properties, but samples of Rudeis Fm. have a tendency toward non-reservoir characteristics. Mean hydraulic radius (MHR) is a capillary pressure-derived parameter that shows a strong correlation with permeability, and defined as the cross-sectional area of the flow divided by the wetted perimeter of a channel or a pipe. Mean hydraulic radius is a measure of a channel flow efficiency. Flow speed along the channel depends on its cross-sectional shape (among other factors). The greater the hydraulic radius, the greater the volume available for fluid flow, the greater the efficiency of the channel and the more volume it can carry; hence, Table 1 and Fig. 7 display that pore system of Kareem Fm. samples is more efficient and permeable than that of Rudeis Fm. samples. Concerning porosity values of the studied samples, the lithological attributes were conducive to clear contrast between the porosity values of the studied samples of the two groups. According to Levorsen (1967), porosity of reservoir rocks is classified as follows:

1-Negligible: $0-5 \% \quad 2$ - Poor: 5-10\% 3 - Fair: 10-15\% 4 - Good: $15-20 \%$ 5-Very good: > 20\%

So, for Kareem Fm. samples, lithological aspects displayed high porosity values that range from 27.5 to $29.9 \%$ and represent a very good reservoir, but Rudeis Fm. samples represent a fair reservoir in terms of porosity where their porosities range from 10.1 to $13.0 \%$, that totally are micropores, (Table 1 and Fig. 8). So porosity of reservoir rocks is affected by lithological attributes.

\section{Petrography}

The studied Kareem Formation (Middle Miocene, depth 2745-2752 m) has been described, as glauconitic, feldspathic quartz wacke, following Pettijohn et al. (1987), where
Fig. 6 Tested samples versus porosity (\%), behind (macropores and micropores)

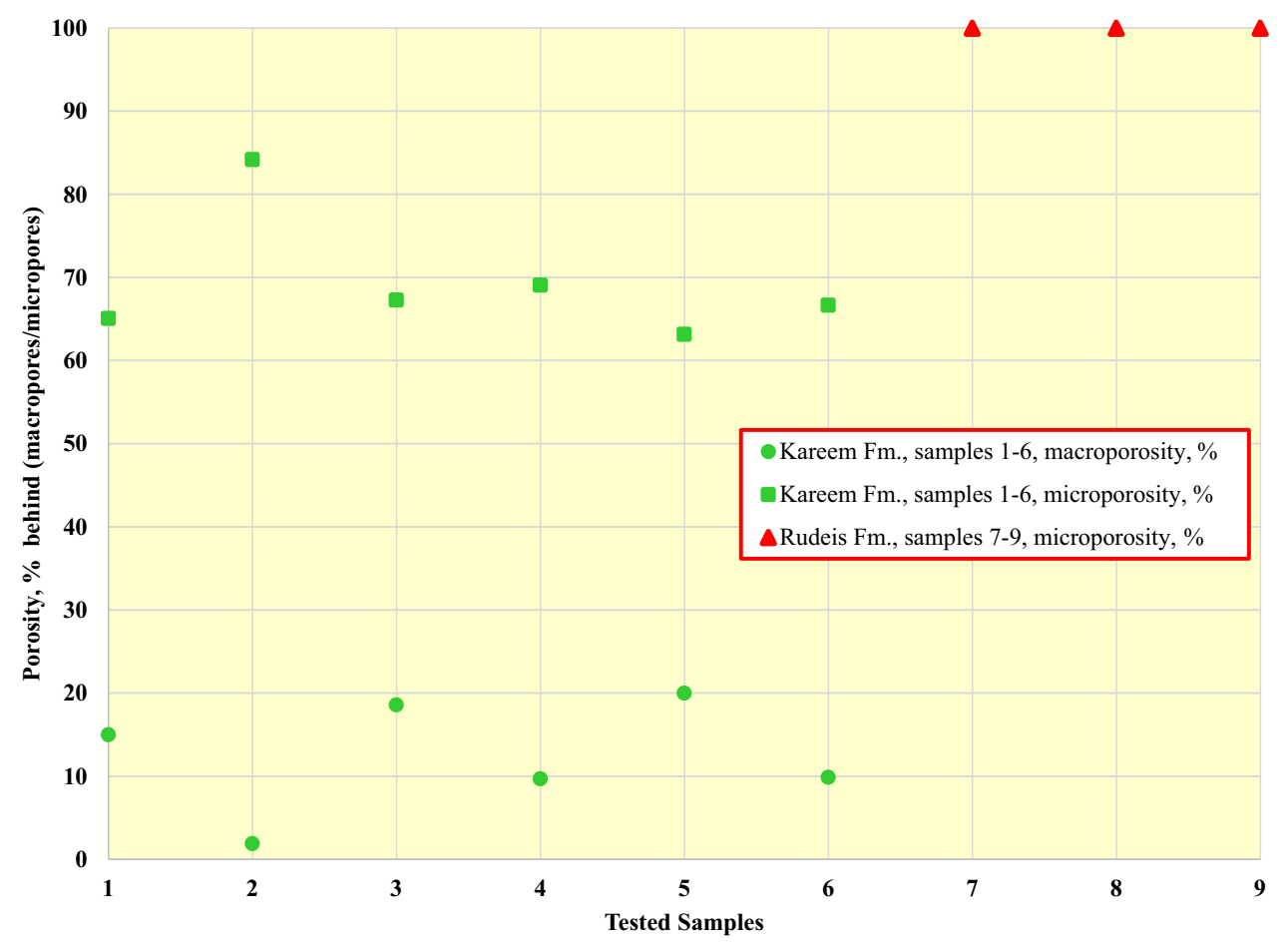


Fig. 7 Tested samples versus MHR, microns

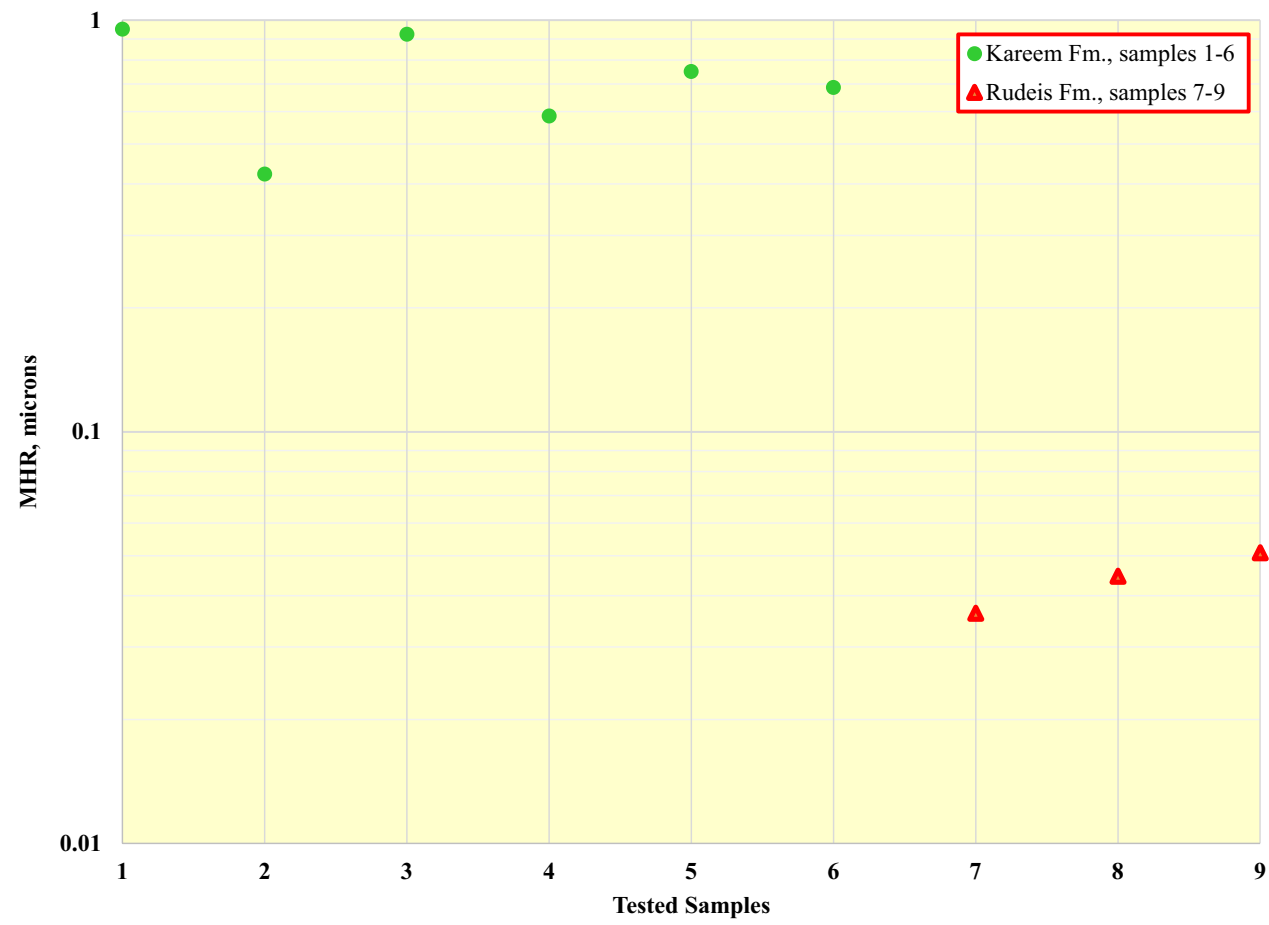

Fig. 8 Tested samples versus porosity, $\%$

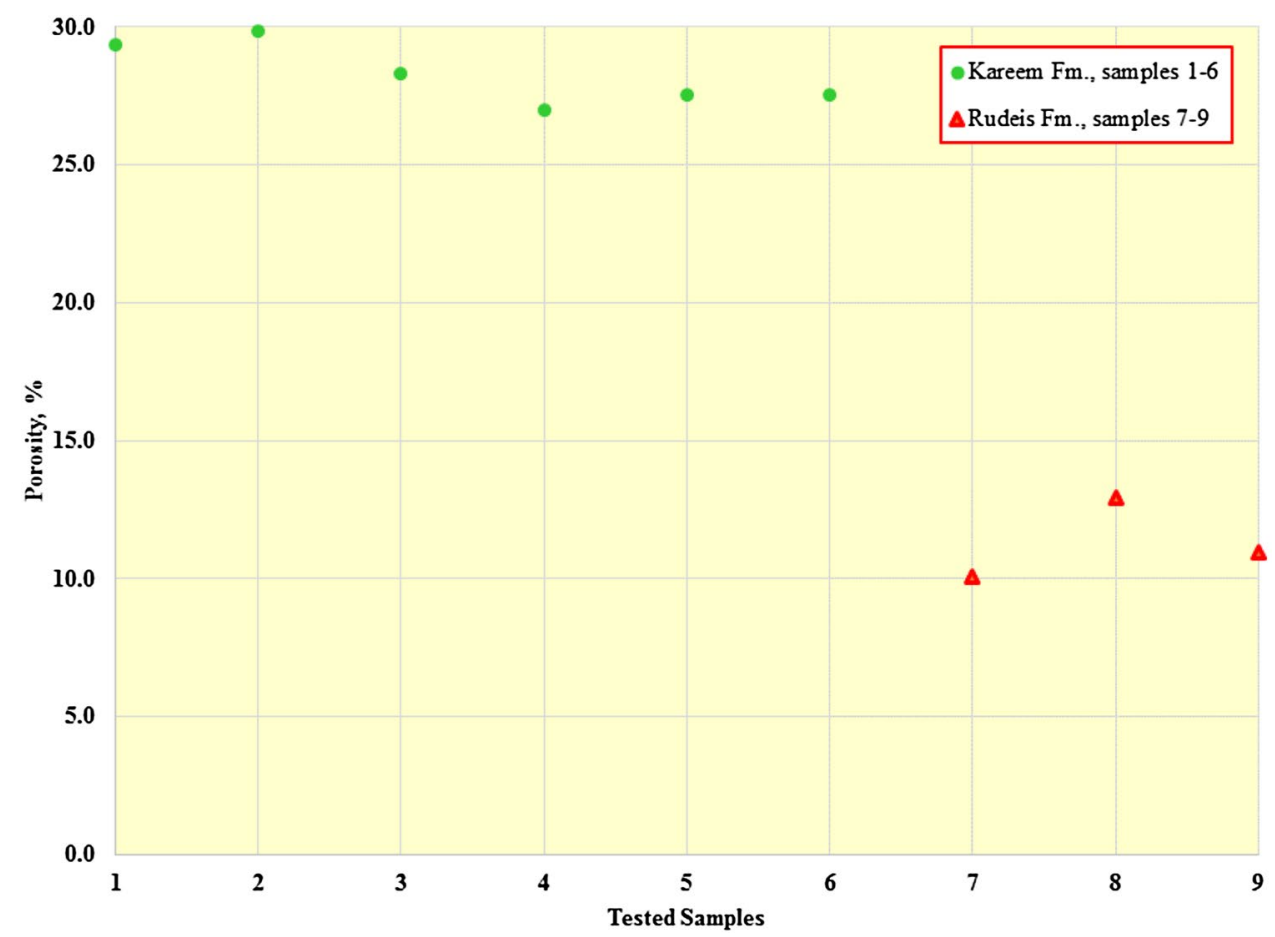

approximately $15 \%$ of their composition is a clay matrix. This sandstone (Fig. 9a, b) is very fine to fine in grain size with rare medium grains, moderately sorted and angular to subrounded in shape. Quartz grains are considered the main constituents and mainly monocrystalline having straight extinction. Potash and plagioclase feldspar varieties follow quartz in amount. The feldspars are either fresh (Fig. 9b) or cracked and altered (Fig. 9d). In addition to these components, considerable amounts of glauconite, fossils and shell fragments are recorded (Fig. 9a). The studied sandstone grains are cemented with clay. On the other hand, the studied Rudeis Formation (Early Miocene, depth 2847-2850 m) represents the carbonate facies. Petrographically, these carbonates can be classified as bioclastic sandy wackestone, 

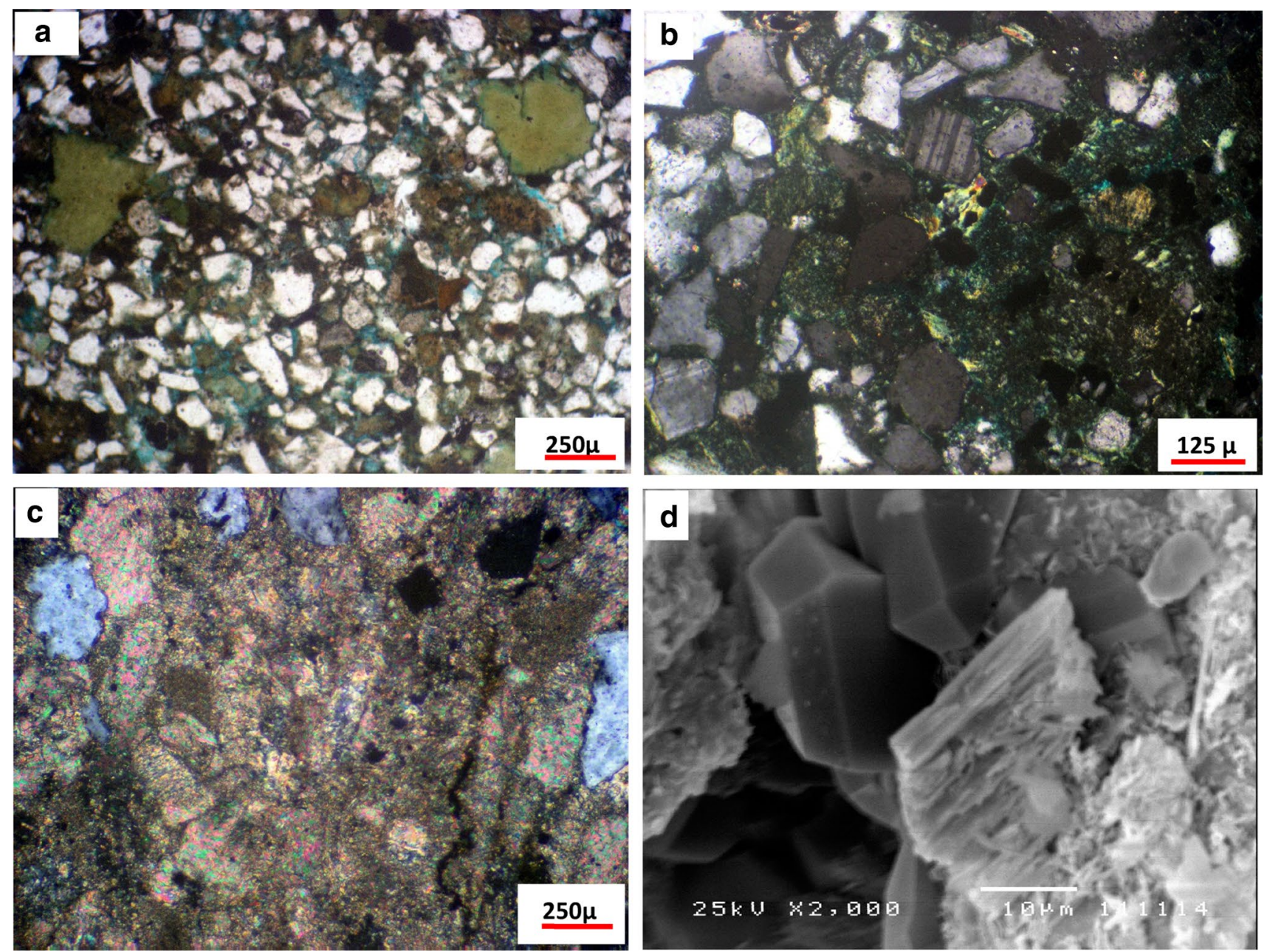

Fig. 9 Photomicrographs a glauconitic quartz wacke of Kareem Fm., PPL. b Fresh and altered K-feldspars in quartz wacke of Kareem Fm., C.N. c Sandy wackestone with foraminiferal and echinoids tests of

Rudeis Fm., C.N. d SEM photograph shows quartz grain overgrowth, altered cracked K-feldspars and clays reduce the pore volume, Kareem Fm

following Dunham (1987), which is composed mainly of microcrystalline carbonate groundmass, with a considerable amount of foraminiferal tests and echinoids. The sand grains are considered as very fine in grain size (Fig. 9c). The studied sandstone was subjected to some diagenetic processes (Fig. 9d), such as mechanical compaction evidenced by deformed feldspar grains, quartz overgrowth and the presence of point and straight grain contacts (MacAulay et al. 1993). Feldspar grains dissolution is another diagenetic effect recorded in the studied samples; this may be attributed to organic acids at deep burial, or it may be due to flushing by meteoric water at shallow depth (Bjorlykke et al. 1989). The presence of fresh feldspars and glauconite in the studied sandstone, sand grains and shallow forms in the carbonate samples indicates shallow marine environment.

\section{Conclusion}

Petrophysical and petrographical examinations were done for a group of samples collected from San El-Hagar-1 well which is located to the East of the Nile Delta. The results showed the presence of two different facies and confirmed the effect of different lithologies on PSD that controls many reservoir properties. It was found that each facies has its own petrophysical properties where the first one is quartz wacke (sandstone facies) of Kareem Fm. of Middle Miocene age and it is composed mainly of quartz grains which are very fine to fine with a medium-sized fraction and moderately to well sorted. The second facies is bioclastic sandy wackestone (calcareous facies) of Rudeis Fm. of Early Miocene age which is composed mainly of the very fine sand size disseminated in microcrystalline carbonate groundmass. The macroporosity and coarser nature of the components of Kareem Fm. samples (relative to those of Rudeis Fm. 
samples) caused wide paths to some extent for fluid flow; in contrast, the finer-sized nature of Rudeis Fm. samples produced a very tight channel system which is hard for fluid flow. Capillary pressure results confirmed that PSD is a function of lithological changes, and also PDF is affected positively or negatively by lithological changes and can be used to assess qualitatively the reservoir flow properties, where Kareem Fm. samples have noticeable flow properties in contrast to Rudeis Fm. samples that have tight flow properties. Bimodal PSD of Kareem Fm. samples reflects different pore systems. Higher percent of macropores in PSD reflects permeability or flow properties higher than that of totally micropores; hence, the more the macropores in a reservoir rock, the better the flow properties. Micropores reflect higher capillary pressure characteristics; hence, the higher the micropores within a reservoir, the higher percent of pores that do not contribute to fluid flow.

Open Access This article is distributed under the terms of the Creative Commons Attribution 4.0 International License (http://creativecommons.org/licenses/by/4.0/), which permits unrestricted use, distribution, and reproduction in any medium, provided you give appropriate credit to the original author(s) and the source, provide a link to the Creative Commons license, and indicate if changes were made.

\section{References}

Abdou AA (2002) The occurrence of late diagenetic pyritic cementation in the Neogene subsurface sediments of Sidi Salim-1 well, Nile Delta. J Fac Educ 27:343-353 (Ain Shams University, Cairo)

Amaefule JO, Altunbay M, Tiab D, Kersey D, Keelan DK (1993) Enhanced reservoir description: using core and log data to identify hydraulic (flow) units and predict permeability in uncored intervals/wells. In: 66th annual SPE conference and exhibitions held in Houston, Texas, October 3-6

Amyx JW, Bass DM Jr, Whiting RL (1960) Petroleum reservoir engineering. McGraw-Hill Book Co., New York, p 97
Bjorlykke K, Ramm M, Saigal GC (1989) Sandstone diagenesis and porosity modification during basin evolution. Geol Rundsch 78:243-268

Cherif OH, El Sheikh H, Mohamed S (1993) Planktonic foraminifera and chronostratigraphy of the Oligo-Miocene in some wells in the Isthmus of Suez and the North-Eastern reach of the Nile Delta, Egypt. J Afr Earth Sci 16(4):499-511

Dunham RJ (1987) Classification of carbonate rocks according to their depositional texture. In WE Ham (ed) Classification of carbonate rocks. Tulsa, OK, AAPG, Mem. 1, pp 108-121

El Sheikh H, Faris M, Shaker F, Kumral M (2016) Mineralogy and source rock evaluation of the marine Oligo-Miocene sediments in some wells in the Nile Delta and North Sinai, Egypt. J Afr Earth Sci 118:163-173

Ismail AA, Boukhary M, Abdel Naby AI (2010) Subsurface stratigraphy and micropaleontology of the Neogene rocks, Nile Delta, Egypt. Geol Croat 63(1):1-26

Kolodzie S Jr (1980) Analysis of pore throat size and use of the Waxman-Smits equation to determine OOIP in Spindle field, Colorado. In: Society of petroleum engineers, 55th annual fall technical conference, paper SPE-9382, $10 \mathrm{p}$

Levorsen AI (1967) Geology of petroleum, 2nd edn. Freeman, San Francisco

MacAulay GE, Burley SD, Johnes LH (1993) Silicate mineral authigenesis in the Hutton and NW Hutton fields: implication for sub-surface porosity development. In: Parker JR (ed) Petroleum geology of Northwest Europe, proceedings of the 4th conference, London, Geological Society of London, pp 1377-1393

Pettijohn FJ, Potter PE, Siever R (1987) Sand and sandstone. Springer, New York, p 553

Sneider RM (1987) Practical petrophysics for exploration and development: AAPG Education Department Short Course Notes, variously paginated

Swanson BF (1985) Microporosity in reservoir rocks-its measurement and influence on electrical resistivity. In: SPWLA 26th annual logging symposium, 17-20 June, Dallas, TX

Zaghloul ZM, Andrawis SF, Ayad SN (1979) New contribution to the stratigraphy of the Tertiary sediments of Kafr El Dawar well No. 1, NW Nile Delta, Egypt. Ann Geol Surv Egypt 9:292-307

Publisher's Note Springer Nature remains neutral with regard to jurisdictional claims in published maps and institutional affiliations. 